Whether decisions on these issues are meaningful with respect to the dimension of sectionalism can be empirically investigated by the application of Guttman sca?ing analysis. Each of a body of decisions has been judged in terms of what has historically been considered the Northern and Southern position. The vote of each justice on each Supreme Court decision is then categorized as "Northern" or "Southern." If the votes can be ordered to conform to the model of a scale (according to prescribed minimum standards), we can infer that a single variable or frame of reference adequately accounts for the total variation in votes among the justices. In this case the terms under which the votes were categorized would justify labeling the single variable "sectionalism." If the scale pattern is achieved we will be able to rank the justices according to the degree to which they are "Northern" or "Southern" in their total voting patterns over a given period of time. We will also be able to characterize the degree to which a given vote on a given decision represents the "Northern" or "Southern" position. By noting the deviations from the perfect scale pattern we will be able to indicate those decisions in which one or more factors other than sectionalism was probably involved, and/or we will be able to pick out any justice who did not view the decisions in the same frame of reference as that applied by most of the other justices. It should also be possible in some cases to demonstrate that the vote of a given justice on a given decision can reasonably be interpreted as representing a position opposite that of other justices who voted the same way. The final step in our analysis will involve demonstration of the degree of relationship between background factors and the scaled "Northernness" and "Southernness" of the justices.

Of course, it is possible that no scale with respect to sectionalism can be demonstrated with these data. Such a negative result would have considerable bearing upon long-accepted historical interpretations of preCivil War Supreme Court decisions.

This technique of scaling analysis applied to other decisions and other issues should make possible characterization of the patterns of Supreme Court decision-making over given periods of time with a great degree of clarity and precision. At the same time, it will provide a more reliable basis for analysis of the relationship of social and economic background factors and judicial behavior.

- -John R. Schmidhauser - -David Gold State University of Iowa

\title{
4. National Support for Behavioral Science
}

\author{
Excerpts from the statement dated Feb., 1958 \\ I. NATURE OF BEHAVIORAL \\ SCIENCE \\ The United States finds itself \\ today in a world situation which \\ demands assessment of every re- \\ source of physical, intellectual, \\ national intellectual and moral \\ power. We identify areas in be- \\ havioral science where accelera- \\ tion of understanding is feasible, \\ and where application of such \\ knowledge to our problems is \\ crucial....
} and moral power. In this memorandum a group of citizens exam.ines the present state of behavioral science and how it can improve international relations and foster
Though the West leads /the Soviet Union 7 in accomplishments in behavioral science at present, and has more and better trained 
scientists, the fact that this field is at an early stage of development, here and in all other nations, means that we could be surpassed by a country which concentrated serious effort to that purpose, if we do not intensify our own efforts.

We must assume the probability of a breakthrough in the control of the attitudes and beliefs of human beings through exceptionally effective educational techniques, drugs, subliminal stimulation, manipulation of motives, or some as yet onrecognized medium. This could be a weapon of great power in. Communist hands, unless comparable advances in the West produce effective countermeasures.

The democratic conviction of the dignity of man and his role in society is a point of view that stimulates development of behavioral science. Concern for the individual has traditionally set problems for philosophers, statesmen, and spiritual leaders. Human behavior represents a complex intermingling of moral and physical considerations, and there is an important region of overlap between behavioral science and the humanities, particularly history, languages, literature, philosophy, and religion. The sciences of man often build on and clarify the wisdom of the humanities, and attempt to formulate and tegt precise laws.

Before.World War I it would have been difficult to point to many applications of basic research in behavioral science that were better than the commonsense judgments of competent individuals. Now there are instances in which basic research has led to important advances that have already had impact on society. These include: intelligence and aptitude testing; techniques to speed learning and increase the effectiveness of education; use of drugs in alleviating or curing certain mental ill- nesses; sample survey methods using mathematical statistics for measuring and predicting social trends; development of increasingly reliable economic indicators fundamental to planning in government and industry; use of group dynamics to improve the efficiency of face-to-face working groups; and many others. Such achievements make for widespread general acceptance-sometimes too enthusiastic and uncritical--of behavioral science. ...

BTehavioral science, directly probing man's central nature, gives promise of increasing his degrees of freedom and expanding his effectiveness and creativity. He can be released from the constriction of life by neurosis and feeblemindedness and the tragedy of psychosis; the limitation of opportunity from inadequate education, associated prejudice and bias; the diminishing of contentment and effectiveness from marital strife, industrial unrest, crime and delinquency; and perhaps most of all, the fear of international conflict which constrains the free expression of the world's peoples. To these central problems of human existence the sciences of man ultimately address themselves....

\section{ILLUSTRATIVE FIELDS OF BEHAVIORAL RESEARCH}

A few examples of the many areas of basic research which can be applied to bettering human life are:

\section{a. Drug Effects on Behav-}

ior. Beginning with the sedatives and anesthetic drugs, and dramatized at present by new tranquillizing and anti-depressant compounds, the field of psychopharmacology is developing with vast potential importance for understanding behavior.... The wide range of possible industrial and medical uses is apparent. 
b. Creativity. Among the highest traits is the ability to produce new intellectual discoveries and artistic products. Such novelty invests life with richness. Methods are being developed for investigating the creative processes of geniuses and others of unusual ability, as well as the effects on them of early experiences and other influences. Quantitative techniques are being worked on for measuring and analyzing inventive processes of discovery. The conditions under which creative activity flourishes and the role of emotions in aiding or blocking it also are being investigated. All this work can lead to expansion of horizons of satisfaction for the artist and creator as well as for those who profit from their endeavors.

c. Human Performance Capabilities and Limitations Under Stress.... Basic research effort is needed to explore not only the limits of human capability under stress, but also the techniques that may be used to improve performance under such influences.

\section{d. Personnel Utilization....}

The demands that will be placed on military and civilian personnel management systems of the future cannot be fulfilled without full application of behavioral science....

e. Decision Process.... The theory and empirical analysis of human decision processes have been vigorously pursued during the last ten years, with promising progress.

f. Group Functioning. ... For a small group to be efficient, each member must contribute the particular technical and social skills expected of him. Basic research on group functioning will almost certainly yield important general principles for group assembly, training, and management, because a number of the technical tools and concepts needed for this effort are now available. g. Measurement of Economic Process.... Measuring the effects of psychodynamic factors on consumer preferences, of political boundaries on the flow of trade, of morale factors on fluctuations in stock values, and of numerous other related elements can eventually put our understanding of economic matters on a basis of more precise science, and so aid in the effective mobilization of resources.

\section{h. Cultural Differences and} Change.... The facts of cultural differences and rapid social change present difficulties to American programs of foreign aid and diplomatic or other communication with peoples abroad. Consequently, it is urgent that we develop a scientific understanding of our own and other ways of life....

i. Man-Machine System Design. ... The advances in technology of mechanical components, such as electronic computers,... . have led to rapid increases in system complexity so that the available knowledge about the capacities and limitations of man in man-machine systems has become more and more inadequate. ... In part, this deficiency results from the fact that only primitive methods are available for comparing the effectiveness of systems in which human beings and equipment must be coordinated. In part, the deficiency is attributable to inadequate scientific information about man's perception, memory, reasoning, and decisionmaking capabilities....

\section{PERSONNEL AND FINAN- CIAL SUPPORT FOR BEHAVIOR- AL SCIENCE}

In this section are presented data showing the vastly disproportionate aid given by the Federal Government to social science when contrasted with aid to the natural sciences. 7 ... 
IV. EXAMPLES OF PROGRAM NEEDS FOR BEHAVIORAL SCIENCE

Most of the research in behavioral science is conducted by individuals working alone or associated with a few colleagues or students. It is desirable to maintain the freedom and diversity which characterize such work. At the same time it is desirable to support the mixed strategy of establishing a number of programs or institutes, organized primarily in universities, which carry out broad and continuing researches focused on a defined target area....

a. An institute for the formulation of general behavior theory....

b. Additional foreign area study centers beyond those that at present exist in American universities....

c. A program for the study of processes such as concept formation. logical eroblem solving. thinking and decision making, including the use of electronic computers to simulate the theoretical models of such functions.

d. A program on the use of social statistics in the development of theories of social change and the prediction of future trends....

e. An institute for the study of the identification, motivation, and education of talented students for useful careers in our society. -.

V. TOOLS AND TECHNIQUES FOR BEHAVIORAL SCIENCE

...While a systematic analysis has not been made of facility requirements, a few examples may be given:

\section{a. Electronic data storage} and retrieval mechanism for the Human Relations Area Files, a compendium of categorized information on several hundred societies of the world....

b. Electronic computer centers, needed for behavioral science research, just as for other areas.

c. Laboratory for research on primate behavior, with facilities for breeding and care of large numbers of animals... .

d. Survey research facilities are essential for many kinds of research....

VI. CONTRIBUTIONS OF BEHAVIORAL SCIENCE TO FOSTERING THE PEACE

... There has been almost no systematic research in behavioral science concerning international relations and diplomacy, negotiation, the prevention of war, or the operation of arms control systems. Yet our most striking diplomatic successes have been mixtures of technology and politics. Such was our open-skies proposal and our atoms-for-peace plan. Human technologies can also be employed. Behavioral scientists could make a specific contribution to this.

Immediate efforts toward national defense should be paralleled by research to discover methods for achieving more permanent and satisfactory means of international agreement. Such discoveries would provide greater security for peoples generally than the invention of any new weapons system.

This is a mission which demands all the wisdom and imagination that behavioral scientists can bring to bear. It is aimed at operating upon the causes rather than the means of war. This can involve efforts to alter the attitudes which create tensions among nations. It also can include objective studies of what other peoples really think of us; clari- 
fication of our own self-image and aspirations; scientific devising of our information programs; development of assistance programs to suit the culture of receiving countries; and reduction of the stress on underdeveloped nations we aid, which results from technological change....

VII. THE PLACE OF BEHAVIORAL SCIENCE IN NATIONAL DEFENSE

... Each of the areas of basic investigation mentioned earlier in this report has military implications, and as the methods of war grow more efficient the need increases for more precision in understanding behavior of men in military systems....

Gross variability in human performance once was acceptable in war, because so many other factors fluctuated. But in modern weapon systems the greatest source of error is man, and consequently a precise science of his acts is urgently required....

VIII. CONTRIBUTIONS OF BEHAVIORAL SCIENCE TO THE NATIONAL STRENGTH AND SPIRIT

The strength of a nation depends on its technical and material assets, and on the scientific research which constantly expands these physical resources. But national strength is equally dependent upon human factors which determine how effectively physical resources are used: the health, morale, and motivation of the population, as well as the formal and informal organization of the society. The well-being and happiness of its citizens are goals of a democratic society, rather than mere means for the attainment of greater material strength. And the productivity of society is dependent upon all these human factors, which are the subject of study of behavioral science....

Fear of the Russians, and measures we must take to meet the Soviet challenge, are not the only motives for supporting such research. Preservation of our advantages and sharing them with the world are other motives even more compelling than fear of a strong enemy.... IT 7 he United States must be strong physically and morally, and therefore needs to pursue such investigations in behavioral science as will contribute to this strength.

--Raymond A. Bauer

Ford Foundation Visiting Professor, Harvard Business School - -George P. Berry, Dean Harvard Medical School --Paul H. Buck, Professor of History and Director of the University Library, Harvard University

--Ralph W. Gerard, Professor of Neurophysiology (Psychiatry) Mental Health Research Institute

University of Michigan $--\mathrm{H}$. Bentley Glass

Professor of Biology

Johns Hopkins University --Rev. C. Leslie Glenn

Mental Health Research Institute University of Michigan --Clyde $K$. Kluckhohn Professor of Anthropology Harvard University

--Donald G. Marquis, Chairman Department of Psychology University of Michigan --Robert K. Merton

Professor of Sociology Columbia University --James G. Miller, Director Mental Health Research Institute University of Michigan --Max F. Millikan, Director Center for International Studies Massachusetts Institute of Technology

--Frank Stanton, President Columbia Broadcasting System --Samuel A. Stouffer, Director Laboratory of Social Relations Harvard University

--Ralph W. Tyler, Director Center for Advanced Study in the Behavioral Sciences

Stanford, California --John C. Whitehorn, Director Department of Psychiatry Johns Hopkins University Medical School 